\title{
DOES UNMET NEED OF FAMILY PLANNING DIFFER IN WOMEN OF URBAN AND RURAL AREAS OF CENTRAL INDIA?
}

\author{
Rujuta Fuke1, Neelam Sukhsohale ${ }^{2}$
}

${ }^{1}$ Associate Professor, Department of Obstetrics and Gynaecology, Government Medical College, Nagpur, Maharashtra, India. ${ }^{2}$ Assistant Professor, Department of Community Medicine, Indira Gandhi Government Medical College, Nagpur, Maharashtra, India.

\begin{tabular}{l}
\hline ABSTRACT \\
BACKGROUND \\
nomen with unmet need are those who are fecund and sexually active but are not using any method of contraception, and report \\
reproductive intentions and their contraceptive behaviour. In this study, an attempt has been made to find out the unmet need of \\
contraception in urban and rural women population and a comparative study to understand the different factors affecting this unmet \\
need of contraception.
\end{tabular}

\section{MATERIALS AND METHODS}

This study was conducted in Rural \& Urban field practice areas under the administrative control of Department of Community Medicine, Indira Gandhi Government Medical College, Nagpur from a period of January 2014 to June 2014. It was a community bas ed cross sectional study. Women were interviewed in a house to house survey from adopted villages of urban and rural health training centres by a pre-tested structured questionnaire. Data was analysed using statistical software Epi Info version 6, year 2009. Total 290 women were enrolled in the study.

\section{RESULT}

The prevalence of unmet need was found to be $43.8 \%$ in urban (spacing 57.8\%, limiting $42.2 \%$ ) and $42.3 \%$ in rural areas (spacing $70.5 \%$, limiting $29.5 \%$ ). The commonest reasons for not using contraceptives in urban area were low perceived risk of pregnancy (42.1\%) followed by health concerns about harmful effects $(35.9 \%)$ and in rural area it was lack of awareness of contraceptive methods (44.8\%) and non-cooperation from family members (12\%). On applying chi square test, the difference was found to be statistically significant $(\mathrm{p}<0.005)$. Moreover, our study also revealed the association of determinants like education, duration of marriage and parity with unmet need. Surprisingly, illiterate urban women had high prevalence of unmet need (6.1\%) as compared to rural women $(2.2 \%)$. With increasing duration of marriage and parity, unmet need was found to be decreasing $(p<0.001)$. Overall a trend of completing family and opting for permanent method of contraception instead of using temporary contraceptives was seen in rural areas.

\section{CONCLUSION}

The high unmet need warrants an effective health promotion program to encourage the uptake of contraceptives especially in women of low education and low parity.

\section{KEYWORDS}

Unmet Need, Contraception, Unmet Need of Spacing, Unmet Need of Limiting.

HOW TO CITE THIS ARTICLE: Fuke R, Sukhsohale N. Does unmet need of family planning differ in women of urban and rural areas of Central India? J. Evolution Med. Dent. Sci. 2018;7(46):5015-5020, DOI: 10.14260/jemds/2018/1116

\section{BACKGROUND}

India is the first country in the world to formulate a demographic goal and implement government sponsored Family Planning Program. In terms of numbers, India is the second largest country in the world, accounting for $16.96 \%$ of the world's population. ${ }^{1}$ India contributes one- fifth of total world population growth. India's population has already crossed the 1 billion mark to reach 1029 million on 1st March, $2001.1,2$ this is a matter of concern not only at the national but at the global level as well. Unmet need of contraception is the major cause behind this population explosion.

'Financial or Other Competing Interest': None.

Submission 06-09-2018, Peer Review 23-10-2018,

Acceptance 31-10-2018, Published 12-11-2018.

Corresponding Author:

Dr. Rujuta Fuke,

\#21, Indrapari,

Ambazari Hill Top,

Nagpur, Maharashtra, India.

E-mail: rujutafuke@yahoo.com

DOI: $10.14260 / j e m d s / 2018 / 1116$

(c) (1) $(9)$
Unmet need for contraception can lead to unintended pregnancies, about one - fourth pregnancies in developing countries are unitended. ${ }^{3}$ these unintended pregnancies lead to unsafe abortions contributing to high maternal mortality and morbidity. For more than 30 years, surveys in less developed countries have asked women about their childbearing intentions and use of family planning. More than 100 million women or $17 \%$ of all married women in less developed countries prefer to avoid pregnancy but are not using any form of family planning services. ${ }^{4}$ These women are said to have "unmet need of family planning." This unmet need tends to depend not only on physical access to services but on numerous other factors like knowledge, education, social structure and myths and beliefs surrounding its use.

In this study, we have tried to find out the unmet need of contraception in urban and rural women population and a comparative study to understand the different factors affecting this unmet need of contraception.

According to the NFHS (2005-2006), nearly 21\% of pregnancies are either unwanted or mistimed. The NFHS-3 
survey (2005-2006) indicated that the unmet need for FP in India was $13 \%$ with $6.2 \%$ for spacing and $6.6 \%$ for limiting. 5

\section{Objectives}

1. To determine the "unmet need for Family Planning" among urban and rural women.

2. To study and compare the met and unmet needs of family planning in urban and rural areas.

3. To study and compare factors determining the unmet need of family planning in study subjects.

\section{Unmet Need of Contraception/Definition}

Women with unmet need are those who are fecund and sexually active but are not using any method of contraception, and report not wanting any more children or wanting to delay the next child. The concept of unmet need points to the gap between women's reproductive intentions and their contraceptive behaviour.

Unmet need of family planning is further divided into unmet need for spacing (Women who want a child after two or more years) and unmet need for limiting (women who want no more children).

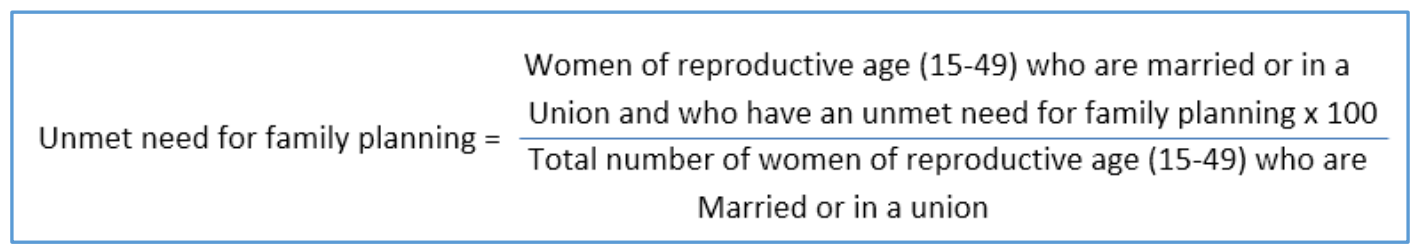

The standard definition of unmet need for family planning includes in the numerator women who are fecund and sexually active but are not using any method of contraception, and do not want any more children or want to delay the birth of their next child for at least two years. 6

\section{MATERIALS AND METHODS \\ Type of Study}

Community based cross sectional study.

\section{Study Subjects}

290 married women in reproductive age group (Urban- 146, Rural - 144)

\section{Study Period}

January 2014 to June 2014.

\section{Study Settings}

This study was conducted in Rural \& Urban field practice areas under the administrative control of Department of Community Medicine, Indira Gandhi Government Medical College, Nagpur from a period of January 2014 to June 2014. It was a community based cross sectional study.

Women were interviewed in a house to house survey from adopted villages of urban and rural health training centres by a pre-tested structured questionnaire.

All eligible women fulfilling the inclusion criteria were enquired about socio-demographic and contraceptive details including met and unmet needs.

\section{Sample Size}

The sample size was taken for convenience for the study.

\section{Inclusion Criteria}

All the women of reproductive age group of 15-45 yrs with active sexual life. The inclusion criteria were women in the reproductive age group of 15-49 age group who were currently married. (Women who were married, who were not using any method of contraception, but who either did not want any more children or wanted to wait for 2 or more-yearsbefore having another child.)

\section{Exclusion Criteria}

1. All pregnant women.

2. Postpartum women upto 6 weeks.

\section{Statistical Methods}

Data was analysed using statistical software Epi Info version 6, year 2009. Data was analysed using Chi square test. Total 290 women were enrolled in the study.

\section{RESULTS}

The study was carried out on 290 women of both urban and rural field practice areas under the administrative control of Department of Community Medicine, Indira Gandhi Government Medical College, Nagpur. Out of which, 146 $(50.3 \%)$ women were interviewed from urban areas and 144 (49.7\%) women were interviewed from rural area. The mean age of study subjects in our study was 27.28 for urban and 26.96 for rural population ( $\mathrm{p}>0.05)$. The mean age of parity was 1.69 for urban and 1.67 for rural area $(p>0.051)$. Mean age of marriage was 5.91 for urban and 5.91 for rural subjects ( $p>0.05)$.

The educational status of the study subjects showed that $3.4 \%$ were illiterate, $9.6 \%$ had primary education, $32.9 \%$ had secondary education, $32.2 \%$ had higher secondary, $18.4 \%$ were graduates and $3.4 \%$ had done postgraduation in urban population. Amongst rural population, $2.8 \%$ were illiterate, $15.3 \%$ had primary education, $42.4 \%$ had secondary education, $31.2 \%$ had higher secondary education, $6.9 \%$ were graduates and $1,4 \%$ had done postgraduation.

The unmet need for family planning in urban area was $43.8 \%$ and $42.4 \%$ in rural area. It showed statistically significant difference. 目 $2=0.06(\mathrm{p}>0.05)$

The unmet need for family planning was found out to be $43.8 \%$ for urban and $42.4 \%$ for rural population. When further divided, it was found that $57.8 \%$ had unmet need for spacing and $42.2 \%$ had unmet need for limiting in urban area whereas $70.5 \%$ had unmet need for spacing and $29.5 \%$ had unmet need for limiting in rural area. The chi square test showed significant co-relation. The difference between unmet need for spacing in urban and rural area was significant. ( $2=2.17$, $\mathrm{p}>0.05$ ).

The commonest reasons for not using contraceptives or family planning methods in urban subjects were low perceived risk of pregnancy (42.1\%) followed by health concerns about 
harmful effects of family planning methods. (35.9\%). Out of total, $23.4 \%$ women were not aware of contraception. According to $17.1 \%$ urban women, no method of contraception is suitable to use for them. Awkwardness to ask for contraception was found in $9.3 \%$ women whereas $7.8 \%$ women found the methods of contraception to be inconvenient to use. Non-cooperation form husband (4.1\%), infrequent sexual activity as a reason (4.6\%), refusal by health care worker to provide family planning services were some of the less common causes of non-use of contraceptive methods. $6.2 \%$ of women were willing for some permanent or long acting reversible contraception but were not using temporary methods in the meantime. Some $18.7 \%$ women had some other miscellaneous reasons.

In rural subjects, the most important reason of unmet need was found out to be unawareness of contraceptive methods in almost $44.8 \%$ of women (? $2=6.23, \mathrm{p}<0.05$ ). Low perceived risk of pregnancy was seen in $18.9 \%$ of rural women. According to $12 \%$ women in this subgroup, there was no suitable method for family planning, $8.6 \%$ were waiting for permanent method or long acting reversible method of contraception, but were not practising any temporary method currently. Around $12 \%$ has to face uncooperative husband and opposition from the elders in the family. Some women (5.1\%) were concerned about the adverse side effects of the different methods. The other reasons for unmet need of contraception were not permitted by religion (5.1\%), awkwardness to seek contraceptive methods (1.7\%), infrequent sexual activity (3.4\%) and other miscellaneous reasons (8.6\%).

Urban Rural Differences in Unmet Need of Contraception:
The unmet need for contraception among urban and rural women was the same but the unmet need to space the births was higher in rural than in urban women.

In both the group of women, as the education level increases, the unmet need of contraception decreases. Contrary to popular beliefs, the illiterate rural women did not have unmet need of contraception both of spacing and limiting than the urban illiterate women who had more unmet need for spacing than limiting. In urban population, the unmet need for limiting was highest in women who had completed secondary education. In urban area, unmet need for limiting was highest in women with secondary education.

As the age of marriage increases, the unmet need of contraception decreases in both urban and rural women. The unmet need for spacing is highest (94.7\%) in urban and rural women in initial five years of marriage. The unmet need for limiting decreases as the years of married life increases.

As the number of living children increases, the unmet need to space the births is decreased but unmet need to limit the births is increased among both urban and rural women.

Women who never used any contraception had higher unmet need of contraception than the women who had used some contraception at some point of time but later on discontinued due to some reasons. This is true for both urban and rural study subjects. The rate of discontinuation of contraception was higher in urban than in rural area. The main reason for discontinuation of the use of contraceptive method was mainly side effects in both urban and rural group. Desire to have more children was the second reason to discontinue in rural women and inconvenience of the method of contraception was seen in urban women.

\begin{tabular}{|c|c|c|}
\hline & No. of Women & Percentage \\
\hline Urban & 146 & $50.3 \%$ \\
\hline Rural & 144 & $49.7 \%$ \\
\hline \multicolumn{2}{|c|}{ Table 1. Distribution of Study Subjects According to Residence } \\
\hline
\end{tabular}

\begin{tabular}{|c|c|c|c|}
\hline & Urban & Rural & P value \\
\hline Mean age & $27.28 \pm 4.76$ & $26.91 \pm 4.65$ & $>0.05$ \\
\hline Mean age of parity & $1.69 \pm 0.64$ & $1.67 \pm 0.69$ & $>0.051$ \\
\hline Mean age of marriage & $5.91 \pm 4.24$ & $5.91 \pm 4.24$ & $>0.05$ \\
\hline \multicolumn{2}{|c|}{ Table 2. Mean Age, Parity and Duration of Marriage of Study Subjects } \\
\hline
\end{tabular}

\begin{tabular}{|c|c|c|}
\hline & Urban (\%) & Rural (\%) \\
\hline Illiterate & 3.4 & 15.3 \\
\hline Primary & 9.6 & 42.4 \\
\hline Secondary & 32.9 & 31.2 \\
\hline Higher Secondary & 32.2 & 6.9 \\
\hline Graduation & 18.5 & 1.4 \\
\hline Postgraduation & 3.4 & \\
\hline \multicolumn{2}{|c|}{ Table 3. Educational Status of Study Subjects } \\
\end{tabular}

\begin{tabular}{|c|c|c|c|c|}
\hline \multicolumn{7}{|c|}{ Occupation n (Urban) \% (Urban) n (Rural) \% (Rural) } \\
\hline Housewife & 117 & 80.1 & 119 & 20 \\
\hline Labourer & 13 & 8.9 & 02 & 13.9 \\
\hline Professional & 05 & 3.4 & 03 & 1.4 \\
\hline Semiskilled & 11 & 7.6 & 52 & 2.1 \\
\hline \multicolumn{5}{|c|}{ Type of Family } \\
\hline Nuclear & 97 & 66.4 & 92 & 36.1 \\
\hline Joint & 49 & 33.6 & 63.9 \\
\hline
\end{tabular}




\begin{tabular}{|c|c|c|c|c|}
\hline \multicolumn{5}{|c|}{ Duration of Marriage } \\
\hline $0-5$ & 87 & 59.6 & 75 & 52.1 \\
\hline $6-10$ & 49 & 33.5 & 44 & 30.6 \\
\hline $11-15$ & 07 & 4.8 & 18 & 12.5 \\
\hline $16-20$ & 03 & 2.1 & 07 & 4.8 \\
\hline \multicolumn{5}{|c|}{ Parity } \\
\hline 1 & 57 & 39 & 40 & 27.8 \\
\hline 2 & 72 & 49.3 & 76 & 52.8 \\
\hline 3 & 05 & 3.5 & 14 & 9.7 \\
\hline 4 & Nil & Nil & 03 & 2.1 \\
\hline none & 12 & 8.2 & 11 & 7.6 \\
\hline
\end{tabular}

\begin{tabular}{|c|c|c|c|c|c|c|}
\hline & \multicolumn{2}{|c|}{$\begin{array}{c}\text { Urban } \\
\text { (n= 146) }\end{array}$} & \multicolumn{2}{c|}{$\begin{array}{c}\text { Rural } \\
(\mathbf{n = 1 4 4 )}\end{array}$} & \multirow{2}{*}{ P value } \\
\hline Met need & 82 & 56.2 & 83 & 57.6 & & \\
\hline Unmet need & 64 & 43.8 & 61 & 42.4 & 0.06 & $>0.05$ \\
\hline Spacing & 37 & 57.8 & 43 & 70.5 & 2.17 & $>0.05$ \\
\hline Limiting & 27 & 42.2 & 18 & 29.5 & & \\
\hline
\end{tabular}

\begin{tabular}{|c|c|c|c|c|c|c|}
\hline \multirow[b]{2}{*}{ Reasons for Not Using Contraception } & \multicolumn{2}{|c|}{ Urban } & \multicolumn{2}{|c|}{ Rural } & \multirow[b]{2}{*}{ ?2 2} & \multirow[b]{2}{*}{ P value } \\
\hline & $(n=64)$ & & $(n=58)$ & & & \\
\hline No Perception of Pregnancy & 27 & 42.1 & 11 & $\begin{array}{c}18.9> \\
0.05\end{array}$ & 7.65 & $<0.05$ \\
\hline Health Concerns- Harmful & 23 & 35.9 & 03 & 5.1 & 17.17 & $<0.001$ \\
\hline Not Aware of Contraception & 15 & 23.4 & 26 & 44.8 & 6.23 & $<0.05$ \\
\hline No Suitable Methods & 11 & 17.1 & 07 & 12 & 0.63 & $>0.05$ \\
\hline Awkwardness to Seek & 06 & 9.3 & 01 & 1.7 & 3.29 & $>0.05$ \\
\hline Inconvenience of Method & 05 & 7.8 & 01 & 1.7 & 2.41 & $>0.05$ \\
\hline Willing for LAPM & 04 & 6.2 & 05 & 8.6 & 0.25 & $>0.05$ \\
\hline Non-Cooperation from Elders & 03 & 4.6 & 07 & 12 & 2.20 & $>0.05$ \\
\hline Infrequent Sexual Activity & 03 & 4.6 & 02 & 3.4 & 0.05 & $>0.05$ \\
\hline Refusal by Healthcare Worker & 03 & 4.6 & Nil & Nil & 2.78 & $>0.05$ \\
\hline Wants to Conceive & 01 & 1.5 & 03 & 5.1 & 1.25 & $>0.05$ \\
\hline Not Permitted by Religion & Nil & nil & 03 & 5.1 & 3.51 & $>0.05$ \\
\hline Low Fertility & Nil & Nil & 02 & 3.4 & 2.24 & $>0.05$ \\
\hline No Concept of Family Planning & Nil & Nil & 03 & 3.4 & 3.39 & $>0.05$ \\
\hline Multiple Reasons & 12 & 18.7 & 05 & 8.6 & 2.60 & $>0.05$ \\
\hline
\end{tabular}

\begin{tabular}{|c|c|c|c|c|c|c|c|c|}
\hline Education & \multicolumn{9}{|c|}{ Urban } & \multicolumn{3}{c|}{ Rural } \\
\hline & $\mathbf{n}$ & met & Unmet & n & met & \multicolumn{2}{c|}{ Unmet } \\
\hline & & & Spacing & Limiting & & & Spacing & Limiting \\
\hline Illiterate & 05 & $03(3.7)$ & $02(5.4)$ & Nil & 04 & $04(4.8)$ & Nil & Nil \\
\hline Primary & 14 & $07(8.5)$ & $05(13.5)$ & $02(7.4)$ & 22 & $14(16.9)$ & $07(16.3)$ & $01(5.55)$ \\
\hline Secondary & 48 & $24(29.3)$ & $14(37.80$ & $10(37.0)$ & 61 & $32(38.6)$ & $18(41.9)$ & $11(61.1)$ \\
\hline Higher Secondary & 47 & $25(30.5)$ & $10(27.1)$ & $12(44.5)$ & 45 & $24(28.9)$ & $15(34.9)$ & $6(33.33)$ \\
\hline Graduates & 27 & $18(22)$ & $06(16.2)$ & $03(11.1)$ & 10 & $07(8.4)$ & $03(6.9)$ & Nil \\
\hline Postgraduates & 05 & $05(6.0)$ & Nil & Nil & 02 & $02(2.4)$ & Nil & Nil \\
\hline
\end{tabular}

\begin{tabular}{|c|c|c|c|c|c|c|c|c|}
\hline \multirow{3}{*}{ Duration of Marriage } & \multicolumn{4}{|c|}{ Urban } & \multicolumn{4}{|c|}{ Rural } \\
\hline & \multirow[t]{2}{*}{$\mathbf{n}$} & \multirow[t]{2}{*}{ Met } & \multicolumn{2}{|c|}{ Unmet } & \multirow[t]{2}{*}{$\mathbf{n}$} & \multirow[t]{2}{*}{ Met } & \multicolumn{2}{|c|}{ Unmet } \\
\hline & & & Spacing & Limiting & & & Spacing & Limiting \\
\hline $0-5$ & 87 & $39(94.7)$ & 35 (94.7) & $13(48.2)$ & 75 & $29(34.9)$ & $39(90.7)$ & $07(38.8)$ \\
\hline $6-10$ & 49 & $36(43.9)$ & $11(40.7)$ & $11(40.7)$ & 44 & $31(37.4)$ & $03(7)$ & $10(55.6)$ \\
\hline $11-15$ & 07 & $05(6.1)$ & $02(7.4)$ & $02(7.4)$ & 18 & $17(20.6)$ & $01(2.3)$ & Nil \\
\hline $16-20$ & 03 & $02(2.4)$ & $01(3.7)$ & $01(3.7)$ & 07 & $06(7.2)$ & nil & $01(5.6)$ \\
\hline
\end{tabular}




\begin{tabular}{|c|c|c|c|c|c|c|c|c|}
\hline \multirow{3}{*}{ Parity } & \multicolumn{4}{|c|}{ Urban } & \multicolumn{4}{|c|}{ Rural } \\
\hline & \multirow[t]{2}{*}{$\mathbf{n}$} & \multirow[t]{2}{*}{ Met } & \multicolumn{2}{|c|}{ Unmet } & \multirow[t]{2}{*}{$\mathbf{n}$} & \multirow[t]{2}{*}{ Met } & \multicolumn{2}{|c|}{ Unmet } \\
\hline & & & Spacing & Limiting & & & Spacing & Limiting \\
\hline 1 & $57(39.0)$ & $28(34.2)$ & $28(75.6)$ & 01 (3.7) & $40(27.7)$ & $09(10.8)$ & $31(72.1)$ & Nil \\
\hline 2 & $72(49.3)$ & $46(56.1)$ & Nil & $26(96.3)$ & $76(52.8)$ & $60(72.2)$ & $01(2.3)$ & $15(83.3)$ \\
\hline 3 & $05(3.4)$ & $05(6.1)$ & Nil & Nil & $14(9.8)$ & $12(14.4)$ & $01(2.3)$ & $01(5.6)$ \\
\hline 4 or more & Nil & Nil & nil & Nil & $03(2.1)$ & $01(1.3)$ & Nil & $02(11.1)$ \\
\hline None & $12(8.3)$ & $03(3.6)$ & $09(24.4)$ & nil & $11(1.3)$ & $01(1.3)$ & $10(23.3)$ & Nil \\
\hline Total & $146(100)$ & $82(100)$ & $37(100)$ & $27(100)$ & $83(100)$ & $83(100)$ & $43(100)$ & $18(100)$ \\
\hline
\end{tabular}

\section{DISCUSSION}

In the present study, $43.8 \%$ of the women in urban and $42.4 \%$ in rural area had unmet need for family planning. The unmet need observed in this study is much higher than the NFHS-3 (2005-2006) data which was $10.8 \%$ for India. ${ }^{3}$ One of the reasons for this high incidence could be that this study was carried with a smaller number of study subjects. Larger sample size or wide geographical inclusion would have given us more comparable results. Bhattacharya et al observed that $42 \%$ had unmet need with $26 \%$ of limiting and $16 \%$ unmet need of spacing. ${ }^{7}$ Present study shows that there is no difference in the unmet need among urban and rural area. Same findings are echoed by a study in Bangladesh (2013) by Islam, et al. however, many studies show that it was higher in rural area (17.4\%) than in urban area (12.6\%). ${ }^{14}$

In our study, the difference between unmet need for spacing in urban and rural area was significant ( $2=2.17$, $\mathrm{p}>0.05$ ). It was more in rural as compared to urban area. Study by Rafiqual Islam, et al 2013 in Bangladesh shows that the unmet need to limit births is almost same for both urban and rural women; on the other hand, unmet need to space births in the rural area is higher than that of in urban area.

Unlike study by Rafiqual Islam, et al 2013 in Bangladesh, the illiterate urban women had no unmet need of contraception. This was in contrast to the study by Andukar $S$ $P$ et al (2006) in study of unmet need of contraception among married women of reproductive age in urban health central field practice area of Government Medical College, Aurangabad found that the unmet need for the contraception was significantly associated with literacy status of the self and of the spouse. ${ }^{8}$

In the present study, age of marriage was found to be associated with unmet need of contraception. As the age of marriage increases, the unmet need of contraception decreases both in urban and rural women. Shrivastava et al (2011) also reported that highest percentage of unmet needs in the initial five years of marriage. It was also seen that women with lesser number of children (less parity) had a higher unmet need in our study. The unmet need for spacing is more with less parity but as the number of living children are more than two or more, the unmet need for limiting increases drastically. Similar findings were made by Shrivastava DK et al (2011) where young age (15-19 yrs) with less parity and less years of married life showed highest percentage of unmet need of family planning. ${ }^{7}$ This can be attributed to the fact that the young couple do not have knowledge of family planning or the awkwardness to use or fear of side effects of contraceptive methods.

Khokar et al (2005) in a study of "Contraceptive use in women from a resultant area in Delhi" showed $30.6 \%$ of the women had unmet need of contraception and in case of $6.3 \%$, opposition from husband and other family members were the reasons for the unmet need, $11.1 \%$ cited the reason to be nonavailability of desired contraceptive and religion was highlighted as a reason by $9.5 \%$ of the subjects. ${ }^{9}$ In the present study, the commonest reasons for not using contraceptive in urban area were low perceived risk of pregnancy (42.1\%) followed by health concerns about harmful effects (35.9\%) and in rural area, it was lack of awareness of contraceptive methods (44.8\%) and un cooperation from husband (12\%).

In a study by Shaheen Rahman, et al 2016, the reasons for unmet need were mostly lack of information (46.2\% in urban, $38.5 \%$ in rural) and health concerns and side effects (30.8\% in urban and $23.1 \%$ in rural area. ${ }^{10}$ Patil SS et al (2010) found that in tribal area of Maharashtra, the most common reason for unmet need was side effects related causes followed by contraceptive method related reasons (lack of availability and awareness) and fertility related reasons (Lactational amenorrhea, desire for more children and infrequent sex). ${ }^{11}$

Overall a trend of completing family and opting for permanent method of contraception instead of using temporary contraceptives was seen in rural areas as also shown by Basu AM in 1993.12

\section{RESULTS}

The mean age of the study population in urban and rural area is 27.28 and 26.91 respectively.

The prevalence of unmet need was found to be $43.8 \%$ in urban (Spacing 57.8\%, limiting 42.2\%) and $42.3 \%$ in rural areas (Spacing 70.5\%, limiting 29.5\%).

$70.7 \%$ of urban and $24.1 \%$ of rural women used temporary methods and $29.3 \%$ of urban and $75.9 \%$ of rural women used permanent methods.

Male condom (47.6\% in urban and $19.3 \%$ in rural) was the most preferred method.

The commonest reasons for not using contraceptives in urban area were low perceived risk of pregnancy $(42.1 \%)$ followed by health concerns about harmful effects (35.9\%) and in rural area it was lack of awareness of contraceptive methods $(44.8 \%)$ and un cooperation from family members (12\%).

On applying chi square test, the difference was found to be statistically significant $(\mathrm{p}<0.005)$.

Moreover, our study also revealed the association of determinants like education, duration of marriage and parity with unmet need.

Surprisingly, illiterate urban women had high prevalence of unmet need (6.1\%) as compared to rural women (2.2\%).

With increasing duration of marriage and parity, unmet need was found to be decreasing $(\mathrm{p}<0.001)$. 
Overall a trend of completing family and opting for permanent method of contraception instead of using temporary contraceptives was seen in rural areas.

\section{CONCLUSION}

The high unmet need warrants an effective health promotion program to encourage the uptake of contraceptives especially by women of low education and low parity.

\section{Recommendation}

The main predictors of unmet need of family planning were found to be lack of knowledge of contraceptive methods, education, parity, age of marriage and drop outs. Therefore, all family planning programs should focus on these drop out population to motivate them to use contraception particularly long acting reversible methods through health education. Fear of side effects needs to be addressed through better counselling by health care professionals. Community leaders should focus more on rural areas. Young and married population deserves special attention because of high unmet need and high fertility. Also, action needs to be taken to improve overall educational status and standard of living of both men and women. The improved educational status will go a long way to achieve the family planning goals.

\section{ACKNOWLEDGEMENTS}

We acknowledge the cooperation of all study subjects.

\section{REFERENCES}

[1] Ross JA, Winfrey WL. Unmet need for contraception in the developing world and the former Soviet Union: an updated estimate. International Family Planning Perspectives 2002;28(3):138-43.

[2] Devi DR, Rostogi SR, Retherford RD. Unmet need for family planning in Uttar Pradesh. National Family Health Surgery Subject Reports 1996;1:3-27.

[3] Haub C, Herstad B. Family Planning Worldwide 2002 Data Sheet: Washington, DC: Population Reference Bureau, 2002.
[4] Srivastava DK, Gautam P, Gautam R, et al. A study to assess the unmet needs of family planning in Gwalior district and to study the factors that help in determining it. Nat J Com Med 2011;2(1):28-31.

[5] International Institute for Population Sciences (IIPS) and Macro International, 2007. National Family Health Survey (NFHS-3), 2005-06, India. Vol. I. Mumbai: IIPS.

[6] Casterline JB, Sinding SW. Unmet need for family planning in developing countries and implications for population policy. Population and Development Review 2000;26(4):691-723.

[7] Bhattacharya SK, Ram R, Goswami DN, et al. Study of unmet need for family planning among women of reproductive age group attending immunization clinic in a medical college of Kolkata. Indian Journal of Community Medicine 2006;31(2):73-5.

[8] Andukar SP, Yadav VB, Dalvi SD. A study of unmet need for family planning among married women of reproduction age in urban health cent field practice area of Govt. Medical College, Aurangabad. Indian Journal of Public Health 2006;50(1):45-6.

[9] Khokhar A, Mehra M. Contraceptive use in women from a resettlement area in Delhi. Indian Journal of Community Medicine 2005;30(1):21-3.

[10] Rahman S. A comparative study of acceptability of contraceptive methods among married women of reproductive age in rural area of Rani Development Block and Urban Slums of Guwahati City. 2007.

[11] Patil SS, Rashid AK, Narayan KA. Unmet needs for contraception in married women in a tribal area of India. Malaysian J Pub Health Med 2010;10(2):44-51.

[12] Basu AM. Cultural influences on the timing of first births in India: large differences that add up to little difference. Population Studies: Journal of Demography 1993;47(1):85-95. 